\title{
ANÁLISE DAS QUESTÕES DA CAIXA DE DÚVIDAS SOBRE SEXO DE UMA ESCOLA DE ENSINO MÉDIO
}

\author{
Thaís Emília de Campos ${ }^{1}$, Raul Aragão Martins ${ }^{2}$ \\ Universidade Estadual Paulista - UNESP. ${ }^{1}$ Mestrado em Educação, Marília - SP. ${ }^{2}$ São José do Rio Preto - SP. E-mail: \\ thais.emilia@hotmail.com
}

\section{RESUMO}

Os PCN recomendam a temática Orientação Sexual seja trabalhada nas escolas com uma abordagem transversal. A conduta sexual envolve além de aspectos biológicos questões psicológicas, geralmente relativas ao comportamento e a conduta sócio moral. Este artigo busca levantar e analisar as questões trazidas pelos alunos de uma escola pública estadual de Ensino Fundamental e Médio deixadas na Caixa de Dúvidas sobre sexo no segundo bimestre de 2013. Estas questões foram analisadas quali-quantitativamente, categorizando-as em aspectos biológicos ou psicológicos da sexualidade. Resultados constataram que a maioria das questões refere-se a aspectos psicológicos, sendo que um quarto das questões refere-se a aspectos morais de consciência e autonomia sobre a sexualidade.

Palavras-chave: orientação sexual, dúvidas, sexualidade e autonomia.

\section{ANALYSIS OF QUESTIONS ABOUT SEX DEPOSITED IN A “DOUBTS BOX” BY HIGH SCHOOL STUDENTS}

\begin{abstract}
The PCN recommend Sexual Orientation theme is worked in schools with a transversal approach. The sexual conduct involves psychological aspects as well as biological issues, usually relating to behavior and conduct sociomoral. This article attempts to survey and analyze the questions raised by students in a state school in elementary and high school left in Box Questions about sex in the second quarter of 2013. Such questions were analyzed qualitative and quantitatively, categorizing them into biological or psychological aspects sexuality. Results found that the majority of the questions refers to psychological aspects, with a quarter of the questions refers to the moral aspects of consciousness and autonomy over sexuality.
\end{abstract}

Keywords: sexual orientation, doubts, sexuality and autonomy. 


\section{INTRODUÇÃO}

A autonomia significa ser governado por si mesmo e a heteronomia significa seguir a opinião de outra pessoa, ela é o objetivo principal da Educação. Segundo Piaget (1994), "toda moral consiste num sistema de regras, e a essência de toda moralidade deve ser procurada no respeito que o indivíduo adquire por essas regras" (PIAGET, 1994, p.23), assim a essência da moral é o respeito às regras a capacidade intelectual de compreender que a regra expressa uma racionalidade. A autonomia aparece com a reciprocidade quando o respeito é mútuo, quando o sujeito adquire a capacidade de elaborar normas próprias que constitui nas relações de cooperação.

Nas relações entre as pessoas que são reguladas pela sociedade temos a sexualidade, que nos Parâmetros Curriculares Nacionais (BRASIL, 1998) apontam fatores importantes para o desenvolvimento humano e dentre eles a sexualidade, como teorizada por Freud, que demonstrou sua importância e sua relação para o desenvolvimento humano. Sabemos, também, o quanto as questões relativas a sexualidade envolvem valores morais e a conduta moral. Desta forma, a sexualidade tem grande importância no desenvolvimento e na psique humana, pois independentemente da potencialidade reprodutiva, relaciona-se com a busca do prazer, necessidade fundamental dos seres humanos. Também entendida como algo inerente, que se manifesta desde o momento do nascimento até a morte, de formas diferentes a cada etapa do desenvolvimento, ela é construída ao longo da vida encontra-se necessariamente marcada pela história, cultura, ciência, assim como pelos afetos e sentimentos, expressando-se então com singularidade em cada sujeito. Indissociavelmente ligado a valores, o estudo da sexualidade reúne contribuições de diversas áreas, como Antropologia, História, Economia, Sociologia, Biologia, Medicina, Psicologia e outras mais (BRASIL, 1998).

Se, por um lado, sexo é expressão biológica que define um conjunto de características anatômicas e funcionais (genitais e extragenitais), a sexualidade é, de forma bem mais ampla, expressão cultural. Cada sociedade cria conjuntos de regras que constituem parâmetros fundamentais para o comportamento sexual de cada indivíduo. Nesse sentido, a proposta de Orientação Sexual dos Parâmetros Curriculares Nacionais considera a sexualidade nas suas dimensões biológica, psíquica e sociocultural (BRASIL, 1998, p.81).

Muitas escolas trabalham a orientação sexual em seus conteúdos formais, incluindo Aparelho Reprodutivo no currículo de Ciências Naturais objetivando a discussão sobre a reprodução humana com conteúdos relativos à anatomia e fisiologia do corpo humano, doenças sexualmente transmissíveis/AIDS, mas 
[...] essa abordagem normalmente não abarca as ansiedades e curiosidades das crianças, pois enfoca apenas o corpo biológico e não inclui as dimensões culturais, afetivas e sociais contidas nesse mesmo corpo (BRASIL, 1998, p.78).

Além das diversas doenças sexualmente transmissíveis (DSTs), o número de adolescentes HIV positivos cresce a cada ano. Embora os adolescentes e jovens tenham cada vez mais informações referente às DSTs e Aids/HIV, há elevado crescimento de transmissão do HIV pelo ato sexual. As estimativas consideram que existam no mundo, aproximadamente 40 milhões de pessoas vivendo com HIV/AIDS, segundo o relatório anual do Programa Conjunto das Nações Unidas sobre HIV/AIDS (BRASIL, 2004).

Ao falar-se em condutas voltadas para a prevenção, pensamos em indivíduos autônomos que possam avaliar as informações, o seu meio ambiente social, as suas potencialidades e limitações.

O tema "Orientação Sexual" faz parte dos Parâmetros Curriculares Nacionais (PCNs), que orientam o trabalho nas escolas do nosso país desde 1997 nos volumes nomeados "Temas Transversais". O texto não fala em obrigatoriedade de uma disciplina específica para o tema, mas sugere que ele faça parte do projeto pedagógico das instituições de ensino (BRASIL, 1998).

Os PCNs definem Educação Sexual como o aprendizado informal que se inicia a partir do nascimento. Envolve as convenções sexuais vigentes na família, na sociedade e as expectativas sobre a sexualidade que se colocam para a criança desde o seu nascimento. Já Orientação Sexual é o conjunto de esclarecimentos e noções transmitidos intencionalmente à criança por outras pessoas, além dos pais. É espaço para discussão e informação que precisa haver nas escolas (SÂO PAULO, 2012). A escola é vista como um espaço propício para trabalhar as questões relacionadas à prevenção de DST's/HIV/Aids e métodos contraceptivos, pois "[...] a escola é um dos principais espaços onde os jovens circulam" (MOSKOVISCI ; CALVETTI, 2008, p.212).

Os adolescentes devem ser capazes de construir normas entre iguais, decidindo pelas normas que quer obedecer principalmente porque participou de sua construção e verificou os benefícios que aquela norma pode ter para o seu grupo (MENIN, 2002). Assim, um programa de orientação sexual elaborado a partir das demandas trazidas pelos adolescentes alvos destas campanhas com base no desenvolvimento da autonomia, na reciprocidade e no respeito mútuo provavelmente atinja com maior amplitude e eficácia os alunos. A norma passa a ser respeitada em função de sua construção e não de posturas autoritárias e higienistas (MOSKOVISCI ; CALVETTI, 2008). 
Com base neste referencial, o presente artigo tem como objetivo analisar as questões trazidas pelos alunos de uma escola de Ensino Médio deixadas na caixa de Dúvidas sobre Sexo. Procurando categorizá-las em biológicas ou psicológicas, afim de traçar uma intervenção sobre orientação sexual atingindo as reais demandas dos alunos.

\section{METODOLOGIA}

Uma unidade da Universidade Estadual Paulista-UNESP preocupada com a questão da sexualidade desenvolve, desde 2006, o projeto "Equipe de Apoio do Ibilce - E ai!?”, em parceria com a Secretaria Municipal de Saúde de São José do Rio Preto - SP, são realizadas pesquisas sobre sexualidade, todas, inclusive esta aprovadas pelo Comitê de Ética e Pesquisa da Unesp. Este projeto visa a prevenção as DST/Aids e gravidez não planejada junto aos seus estudantes.

Nesta escola temos uma caixa de dúvidas que fica em local de fácil acesso aos alunos e discreto, a fim de depositarem questões e dúvidas sobre sexo de forma anônima, preservando a privacidade do autor. Estas questões são respondidas através do mural, do facebook do $E$ ai?, de e-mail, de palestras e de grupos de tira-dúvidas.

Este artigo traz a análise das questões depositadas na Caixa de Dúvidas no período de abril de 2013 a junho de 2013 pelos alunos da etapa 2 do Ensino Fundamental e Ensino Médio. Esta caixa foi colocada em um local de fácil acesso a todos os alunos e para incentivar o seu uso uma equipe de alunos foi a todas as salas falar sobre ela.

Foram depositados 58 bilhetes, que depois de digitados em uma planilha eletrônica constatou-se a existência de 79 dúvidas, que posteriormente foram classificadas em duas categorias: questões que abarcam aspectos biológicos e questões que abarcam aspectos psicológicos.

A categoria aspectos biológicos teve como subcategorias patologia, fisiologia e anatomia. Sendo assim, as dúvidas sobre DST/HIV/Aids foram subcategorizadas como patologia; dúvidas que envolviam questões sobre o funcionamento do corpo, como por exemplo, período fértil, gestação, menstruação, ejaculação, pertencem a subcategoria fisiologia; e dúvidas que abarcam questões sobre os órgãos sexuais e o corpo pertencem a subcategoria anatomia.

A categoria aspectos psicológicos foi subcategorizada em consciência/autonomia, afetividade, prazer e dor (sensações), e comportamento. Sendo assim, as questões que se referem a prevenção, respeito, planejamento da vida sexual e afetiva pertencem a subcategoria consciência/autonomia; as questões que envolvem afetos e sentimentos (amor, paixão, raiva) foram subcategorizados como afetividade; dúvidas que envolvem questões sobre dor na primeira 
relação, prazer e orgasmo no ato sexual, formas de prazer (sexo oral e anal) foram subcategorizadas como prazer/dor (sensações); e dúvidas que abarcam questões sobre relacionamento hetero afetivo e homo afetivo foram categorizadas como comportamento. Foram calculadas as frequências e porcentagens das categorias. Duas dúvidas traziam apenas frases sem sentido e foram descartadas, resultando em 77 dúvidas válidas.

\section{RESULTADOS}

Com a tabulação dos dados pode-se constatar que das 77 dúvidas, 61,0\% delas referem-se a aspectos psicológicos, 39,00\% referem-se a aspectos biológicos (Tabela 1).

Tabela 1. Frequência e porcentagem das respostas por categoria da dúvida

\begin{tabular}{|c|c|c|c|}
\hline Categoria & & $\boldsymbol{F}$ & $\%$ \\
\hline \multicolumn{4}{|l|}{ Psicológica } \\
\hline Consciência / autonomia & & 14 & 29,8 \\
\hline Afetividade & & 2 & 4,3 \\
\hline Prazer e dor (Sensações) & & 10 & 21,3 \\
\hline Comportamento & & 19 & 40,4 \\
\hline \multirow[t]{2}{*}{ Mito } & & 2 & 4,3 \\
\hline & Subtotal & 47 & 100,0 \\
\hline \multicolumn{4}{|l|}{ Biológica } \\
\hline Fisiologia & & 20 & 66,7 \\
\hline Anatomia & & 6 & 20,0 \\
\hline \multirow[t]{2}{*}{ Patologia } & & 4 & 13,3 \\
\hline & Subtotal & 30 & 100,0 \\
\hline
\end{tabular}

Na categoria sobre os aspectos psicológicos predomina as dúvidas sobre comportamento, que representam 40,0\% delas, tendo como exemplo as seguintes perguntas: "porque os homens dormem depois que transam?", "porque as mulheres gemem?", "Sinto que os meus olhos vão se esbodegar pra fora na hora do love. É normal?". A categoria "consciência/autonomia" representa 29,8\% dessas dúvidas, exemplos de questões: "Sexo é importante? O que causa fazer?", “Com quantos anos pode fazer sexo?"," É possível na hora H o homem urinar dentro da mulher? Se possível quais os danos?". Em relação as dúvidas da categoria "Biológica" predomina as relativas a fisiologia (66,7\%), seguidas de anatomia (20,0\%), como exemplos temos: "Enconchar engravida?", "É possível um homossexual operado engravidar?", "Mesmo usando camisinha tem uma possibilidade de engravidar?". 


\section{DISCUSSÃO}

Trabalhar a temática Orientação Sexual nas escolas ainda é tabu para muitos educadores. Quando abordam esta temática, o discurso geralmente parte dos professores de biologia ou nas matérias de ciências, remetendo-se à doenças e gravidez precoce

O desejo de experimentar os beijos, as carícias e o prazer sexual é tão fascinante que uma palestra ou aula sobre DST's, HIV e métodos anticoncepcionais, por exemplo, não faz sentido para o adolescente abordando somente os aspectos biológicos, já que constatamos que a maioria das questões trazidas na caixa de dúvidas referem-se a aspectos psicológicos (61,0\%) e somente 39,0\% para os aspectos biológicos. O que demonstra o quanto a maioria das preocupações dos adolescentes referem-se a aspectos psicológicos e não biológicas.

A compreensão de como jovens percebem e conduzem a sua vida sexual é um fator importante para o desenvolvimento de trabalhos preventivos, pois esta falta de conhecimento tem levado a estratégias de prevenção que ou trazem uma linguagem metafórica, o que dificulta a compreensão delas, outras vezes, vulgariza e instiga preconceitos de inúmeras ordens (LIMA ; CARDOSO, 1999).

$\mathrm{Na}$ subcategorias referentes ao aspecto psicológico, temos os seguintes dados: maior predominância nas questões que referem-se a comportamento sexual com $40,4 \%$ delas, seguindo dos relacionados a consciência e autonomia com $29,8 \%$, depois a prazer e dor (sensações) com $21,3 \%$, afetividade e mito ambos com $4,3 \%$. Já nas subcategorias referentes aos aspectos biológicos, temos os seguintes dados: maior predominância nas questões que referem-se a fisiologia com $66,7 \%$, depois as referentes a anatomia com $20 \%$ e por último as referentes a patologia com $13,3 \%$.

O estudo de Ayres (2002) confirma que as campanhas iniciais com métodos terroristas e a segregação e discriminação dos doentes acometidos pela patologia, perdem espaço social e apresentam-se com poucos resultados; o histórico do perfil da epidemia do HIV nos mostra a necessidade de uma abordagem cada vez mais ampla e precoce, justificando a importância de se trabalhar o adolescente. E os dados da caixa de dúvida apresentam apenas $5 \%$ das questões relativas a preocupações com HIV e outras DST'S.

Pesquisas atuais, como a de Ayres (2003) e Jeolás (2006) mostram que os adolescentes e jovens fazem parte de um grupo em situação de vulnerabilidade o que nos força a repensar a prevenção em saúde, estendendo o entendimento da prevenção para o espaço educacional, objetivando estimular o desenvolvimento da autonomia do jovem diante de sua vida sexual. Mas, os dados porém demonstraram que um quarto das questões referem-se a aspectos sobre 
consciência e autonomia, ou seja, os adolescentes estão preocupados e com anseios em relação as decisões e responsabilidades em relação a sua sexualidade.

Os dados coletados na Caixa de Dúvida demonstram que há maior preocupação sobre o tema sexo por parte dos alunos no que se refere a aspectos psicológicos do que aos biológicos, porém, mesmo com as orientações do PCN's da abordagem transdisciplinar dos temas transversais, o tema Sexualidade continua sendo, na prática responsabilidade dos professores de biologia, que não conseguem abarcar todas as angústias dos adolescentes, pois envolvem questões transdisciplinares como comportamento, sensações, medos, inseguranças, moral e cultura.

Em relação a moral temos a questão da autonomia e consciência das ações e condutas. $\mathrm{Na}$ caixa de dúvidas tivemos $25 \%$ das questões sobre sexo referindo-se a temas sobre autonomia e consciência, envolvendo autocuidado e cuidado com o parceiro, privacidade e exposição, fator este que demonstra a necessidade de se trabalhar aspectos relativos a educação moral quando aborda-se o tema sexualidade, envolvendo a autonomia, o respeito mútuo e a cooperação.

\section{CONCLUSÃO}

A sexualidade deve ser trabalhada nas escolas transdisciplinarmente e envolver aspectos não somente biológicos, envolve a todos da escola em todas as funções e disciplinas, principalmente ética. Sexualidade está diretamente relacionada ao trabalho de educação para autonomia e respeito mútuo, objetivo principal da educação. Buscando fugir e desmitificar o olhar apenas higienista e medicalizante da sexualidade e do corpo, tirando-a do patamar apenas de questão de saúde pública de controle epidêmico e colocando-o no patamar de algo natural e inerente ao desenvolvimento do ser humano, tanto nas questões de DST's e Aids, de gravidez na adolescência e de gravidez não planejada, de gênero, das formas de prazer, e na adequação do corpo no caso das cirurgias de transsexualidade e hermafroditismo, pensando no respeito e direito ao que foge o binarismo de gêneros e comportamentos.

A questão da Orientação Sexual na escola é muito complexa e ampla, envolve diversas questões éticas, morais, médicas, humanas, sociais, culturais e políticas. Deve ser profundamente estudada pelos educadores principalmente possibilitando a discussão dos aspectos morais que normalmente recebem uma postura de "neutralidade" para focar apenas os aspectos biológicos ou de medicalização sobre as condutas. A orientação sexual deveria ser vista como uma oportunidade de utilizar os dilemas que envolvem a sexualidade para trabalhar os aspectos de Educação e Desenvolvimento Moral. 


\section{REFERÊNCIAS}

AYRES, José R. C. M. Adolescência e AIDS: avaliação de uma experiência de educação preventiva entre pares. Interface - Comunic, Saúde, Educ, v. 7, n. 12, p. 113-28, 2003. AYRES, José R. C. M. Práticas educativas e prevenção de DST/AIDS: lições aprendidas e desafios atuais. Interface Comunic, Saúde, Educ, v.6, n. 11, p. 11-24, 2002.

BRASIL. Parâmetros Curriculares Nacionais Brasília: MEC/SEF, 1998.

JEOLÁS, L. S. Juventude, sexualidade e Aids: aspectos simbólicos da percepção do risco e da vulnerabilidade. In: FIGUEIRÓ, M. N. D.; RIBEIRO, P. R. M. (Org.) Adolescência em questão: estudos sobre sexualidade. Araraquara: FCL - UNESP Laboratório Editorial; São Paulo: Cultura Acadêmica Editora, 2006.

LIMA e CARDOSO. Campanhas do governo federal em duas décadas de epidemia. In: III Congresso Nacional de prevenção às DST/Aids. Anais. Rio de Janeiro, RJ, 1999. p.171.

MENIN, Maria Suzana de Stefano. Valores na Escola. São Paulo: Educação e Pesquisa, v.28, n.1, p. 91-100, jan./jun. 2002.

MOSKOVICI, J. M. ; CALVETT, P. Ü. Formação de multiplicadores para a prevenção das DST/AIDS numa universidade espanhola. Psicologia Ciência e Profissão. v. 28 n.1, p.210-217. Brasília, 2008.

PIAGET, Jean. O juízo moral na criança. São Paulo, SP: Summus, 1994. (Original publicado em 1932).

SÃO PAULO. Especial: Sexualidade e Orientação Sexual [09/2010]. (http://www.bibliotecavirtual.sp.gov.br/especial/201009-sexualidade.php), acesso em 25/09/2012), 2012. 